\title{
胺甲酰氟促进的镍催化非活化烯烃的不对称胺甲酰基-芳基化反应
}

\author{
伍贤青陈宜峰* \\ (华东理工大学化学与分子工程学院 上海 200237)
}

\section{Carbamoyl Fluoride-Promoted Ni-Catalyzed Asymmetric Carbamoyl-Arylation of Unactivated Alkenes}

\author{
Wu, Xianqing Chen, Yifeng*
}

(School of Chemistry and Molecular Engineering, East China University of Science \& Technology, Shanghai 200237)

过渡金属催化烯烃的不对称双碳官能团化反应提 供了一种快速构建手性化合物的简便方法，近年来备受 化学研究者们的关注 ${ }^{[1]}$. 目前主要的研究思路是通过设 计含苯环的底物现场生成芳基金属物种, 来进行不活泼 烯烃的分子内不对称双官能团化反应. 对于含有非苯并 底物的非活化烯烃的不对称双碳官能团化反应来实现 季碳手性中心的构建，已报道的仅有少数通过酰基金属 中间体的策略 ${ }^{[2-4]} .2010$ 年, Takemoto 等 ${ }^{[2]}$ 报道了一例钯 催化烯烃和胺甲酰氰的不对称胺酰基氰化反应来构建 季碳手性中心, 但是反应的效率及对映选择性都比较低 $(15 \%, 27 \% e e)($ Scheme 1, b). $\gamma$-内酰胺作为核心骨架广 泛存在于一系列活性天然产物或者药物分子中, 但目前 其合成特别是对 $\alpha$-位含季碳手性中心的 $\gamma$-内酰胺的高 对映选择性合成, 仍然存在巨大的挑战 ${ }^{[5]}$.

最近, 南开大学化学学院叶萌春课题组利用稳定的 胺甲酰氟为底物, 使用商业易得的芳基硼酸作为偶联组 分, 实现了镍催化非活化烯烃的不对称氧化还原中性的 胺甲酰基-芳基化反应，高收率高对映选择性地合成了 一系列含有手性季碳中心的 $\gamma$-内酰胺化合物 ${ }^{[6]}$.

考虑到常用的胺甲酰氯化合物在反应中容易脱羰, 作者采用更加稳定的胺酰氟作为起始底物. 然而该设想 存在的潜在挑战在于, 胺甲酰氟的反应活性较低, 氟化 物不易发生转金属历程. 因此作者选用 $\mathrm{N}$ 上保护基为位 阻更大的 2,4,6-三甲基苄基 $\left.{ }^{T M} \mathrm{Bn}\right)$ 的胺酰氟作为模板底 物, 以期通过增加位阻效应来促使胺甲酰基金属物种更 加靠近烯烃部分, 从而有利于分子内的迁移插入. 作者 发现使用手性 BINAP 配体和 Ni(cod $)_{2}$ 组合可高收率高 对映选择性地得到目标产物. 该反应具有优异的官能 (a) Arylmetal-involved difunctionalizaiton of 1,1-substituted alkene

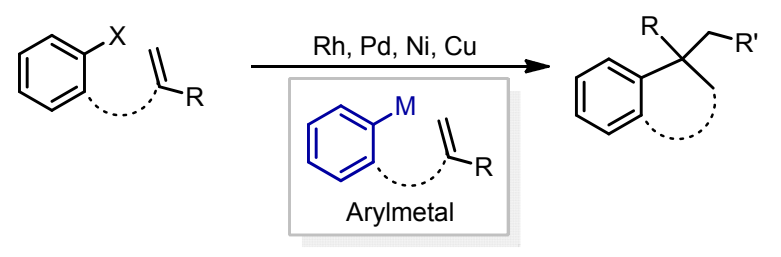

(b) Acylmetal-involved difunctionalizaiton of 1,1-substituted alkene

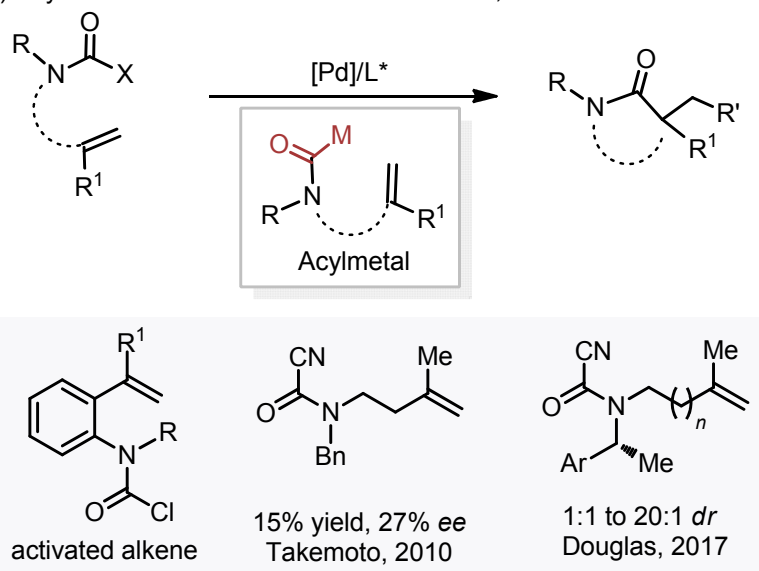

图式 1 非活化烯烃的不对称双碳官能团化反应

Scheme 1 Asymmetric difunctionalization of unactivated alkene

团容忍性以及广泛底物适用范围(Scheme 2).

为了更好地突出胺酰氟的促进作用, 作者使用胺酰 氯作为底物在标准条件下进行反应, 发现反应的收率及 $e e$ 值都大幅度降低 $(40 \%, 54 \% e e)$ (Scheme 3). 此结果进 一步说明了 $\mathrm{F}$ 原子的存在有助于提升反应活性及对映选 择性.

* Corresponding author. E-mail: yifengchen@ecust.edu.cn. Published online January 29, 2021. 


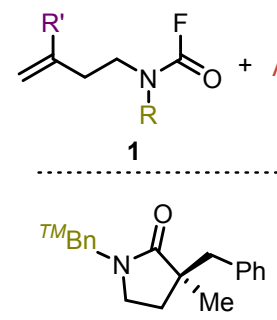

3a, $80 \%, 96 \%$ ee

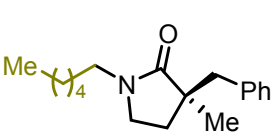

3b, $56 \%, 93 \%$ ee

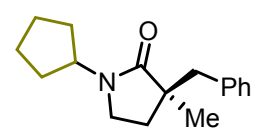

3c, $82 \%, 91 \%$ ee<smiles>C[C@]1(Cc2ccccc2)CCN(C2CCCCCC2)C1=O</smiles>

3d, $70 \%, 87 \%$ ee<smiles>CC(C)(C)N1CC[C@@](CCOc2ccccc2)(Cc2ccccc2)C1=O</smiles>

3e, $75 \%, 97 \%$ ee

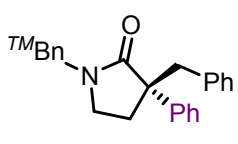

3f, $58 \%, 94 \%$ ee<smiles>C[C@]1(Cc2cccc3ccccc23)CCN(Cc2ccccc2)C1=O</smiles>

3g, $63 \%, 95 \%$ ee

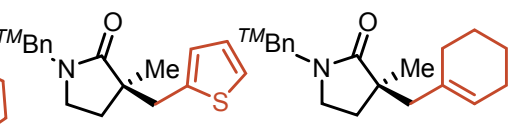

3h, $45 \%, 95 \%$ ee

3i, $84 \%, 90 \%$ ee
图式 2 代表性底物范围

Scheme 2 Representative substrates scope

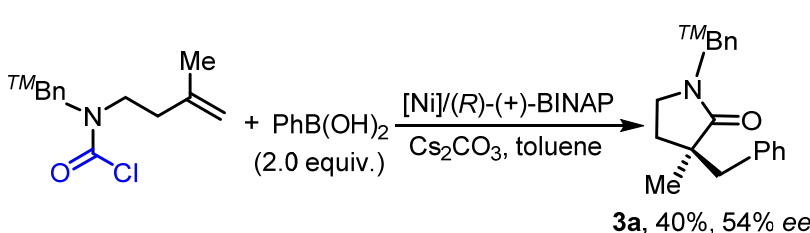

图式 3 胺酰氯的对比反应

Scheme 3 Comparison with carbamoyl chloride

随后，作者通过烯烃及烷基取代的胺甲酰氟与苯硼 酸的反应速率对比、环化步骤中间体的捕捉及其反应性 考察实验, 提出以下可能的反应机理: 首先, 胺酰氟和 零价镍发生氧化加成, 得到二价的胺酰基镍中间体 $\mathbf{A}$; $\mathbf{A}$ 与苯嗍酸直接发生 Suzuki 偶联生成 B 的速率相当慢, 而对分子内烯烃发生迁移插入的速度很快, 因此反应的 优势路径是中间体 $\mathbf{A}$ 发生分子内环化得到二价烷基镍 中间体 $\mathbf{C}$; 随后, 中间体 $\mathbf{C}$ 与芳基嗍酸发生转金属
得到中间体 D, D 还原消除得到产物 $\mathbf{3}$ 的同时游离出零 价镍，完成催化循环(Scheme 4).

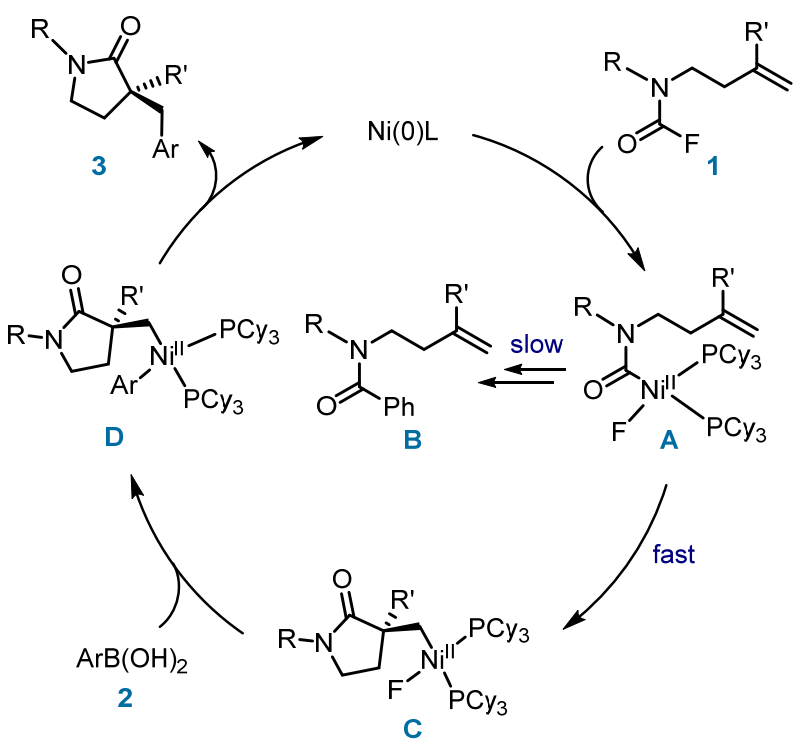

图式 4 推测的反应机理

Scheme 4 Proposed mechanism

总之, 叶萌春团队利用胺甲酰氟独特的反应性，发 展了镍催化非活化烯烃与芳基硣酸的不对称胺甲酰基芳基双官能团化反应，以高收率高对映选择性地合成了 一系列含季碳手性中心的 $\gamma$-内酰胺化合物. 这是胺甲酰 氟参与不对称环化偶联的反应，这为日后的不对称羰基 化反应提供了新的研究思路.

\section{References}

[1] Dhungana, R. K.; KC, S.; Basnet, P.; Giri, R. Chem. Rec. 2018, 18, 1314.

[2] Yasui, Y.; Kamisaki, H.; Ishida, T.; Takemoto, Y. Tetrahedron 2010, 66, 1980.

[3] Dreis, A. M.; Otte, S. C.; Eastwood, M. S.; Alonzi, E. R.; Brethorst, J. T.; Douglas, C. J. Eur. J. Org. Chem. 2017, 2017, 45.

[4] Wu. X.; Qu, J.; Chen, Y. J. Am. Chem. Soc. 2020, 142, 15654.

[5] Ye, L.-W.; Shu, C.; Gagosz, F. Org. Biomol. Chem. 2014, 12, 1833.

[6] Li, Y.; Zhang, F.-P.; Wang, R.-H.; Qi, S.-L.; Luan, Y.-X.; Ye, M. J. Am. Chem. Soc. 2020, 142, 19844.

(Zhao, C.) 